01,07

\title{
Влияние динамической прочности материала на его эрозионную стойкость
}

\author{
() А.Д. Евстифееев ${ }^{1,2}$, И.В. Смирнов ${ }^{2}$, Ю.В. Петров ${ }^{1,2,3}$ \\ ${ }^{1}$ Научно-исследовательский институт механики Национального исследовательского \\ Нижегородского государственного университета им. Н.И. Лобачевского, \\ Нижний Новгород, Россия \\ ${ }^{2}$ Санкт-Петербургский государственный университет, \\ Санкт-Петербург, Россия \\ ${ }^{3}$ Институт проблем машиноведения РАН, \\ Санкт-Петербург, Россия \\ E-mail: ad.evstifeev@gmail.com
}

Поступила в Редакцию 15 апреля 2020 г.

В окончательной редакции 15 апреля 2020 г.

Принята к публикации 23 апреля 2020 г.

Повышение статической прочности материалов, применяемых в экстремальных условиях эксплуатации, не позволяет судить о надежности конечных изделий. В статье, на примере алюминиевого и титанового сплавов, показаны особенности деформирования материала, проявляющиеся с ростом скоростей деформации. Обсуждается возможность выбора материала под заданные условия эксплуатации в рамках структурновременного подхода.

Ключевые слова: ударное воздействие, критерий инкубационного времени, эрозионное истирание, интенсивная пластическая деформация, алюминий, титан.

DOI: 10.21883/FTT.2020.10.49897.088

\section{1. Введение}

Современная авиакосмическая отрасль находится на пороге внедрения революционных методов и подходов к проектированию воздушных судов. Для облегчения конструкции все чаще применяются композитные материалы совместно со сплавами легких цветных металлов взамен стальных конструкций. При этом в части ответственных узлов конструкции предпочтение отдается титановым сплавам, несмотря на их больший вес по сравнению с алюминиевыми материалами. Данный подход позволяет повысить прочность и надежность конструкции при условии работы в области квазистатических нагрузок. При этом не уделяется должного внимания работе материала при динамических нагрузках, несмотря на наличие существенных особенностей деформирования материала, возникающих при повышении скорости деформирования [1-6]. Экстраполяция свойств материала на область высоких скоростей деформации, как правило дает ошибочные результаты, и данный подход не выдерживает критики в области проектирования ответственных, динамически нагруженных элементов.

В работе рассматриваются результаты экспериментов, полученные на эрозионной установке аэродинамического типа [7] и на башенном копре с ускорителем [8]. На примере алюминиевого сплава $\mathrm{AMg6}$ и титанового сплава VT1_0 показаны области применения данных материалов при экстремальных условиях нагружения, а также рассмотрены пути повышения прочности алюминиевого сплава, не снижающие динамическую прочность материала. Предложенный экспериментально аналитический подход, основанный на структурно временном подходе позволяет не только выбирать материалы для экстремальных условий эксплуатации, но и формирует принципы для возможности повышения прочности материала.

\section{2. Материал и методы исследования}

В качестве объекта изучения были выбраны титановый сплав ВТ1 и алюминиевый сплав AMg6, в исходном и ультрамелкозернистом состоянии [9]. Повышение прочностных свойств алюминиевого сплава было осуществлено методами равноканального углового прессования (РКУП) по маршруту Вс при $200^{\circ} \mathrm{C}$. Образцы имели квадратное сечение $9 \times 9 \mathrm{~mm}$ при длине образца $55 \mathrm{~mm}$. После четырех проходов материал показал оптимальные характеристики прочности и пластичности. Механические характеристики исследуемых материалов приведены в таблице. Диаграммы деформирования представлены на рис. 1.

По представленным данным видно, что максимальной прочностью и пластичностью обладает титановый сплав. Обработка алюминиевого сплава методами РКУП позволила повысить предел текучести и кратковременной прочности на 20\%, сохранив при этом пластичность на высоком уровне.

При этом, как было отмечено выше, высокие значения прочности и пластичности в области квазистатического 


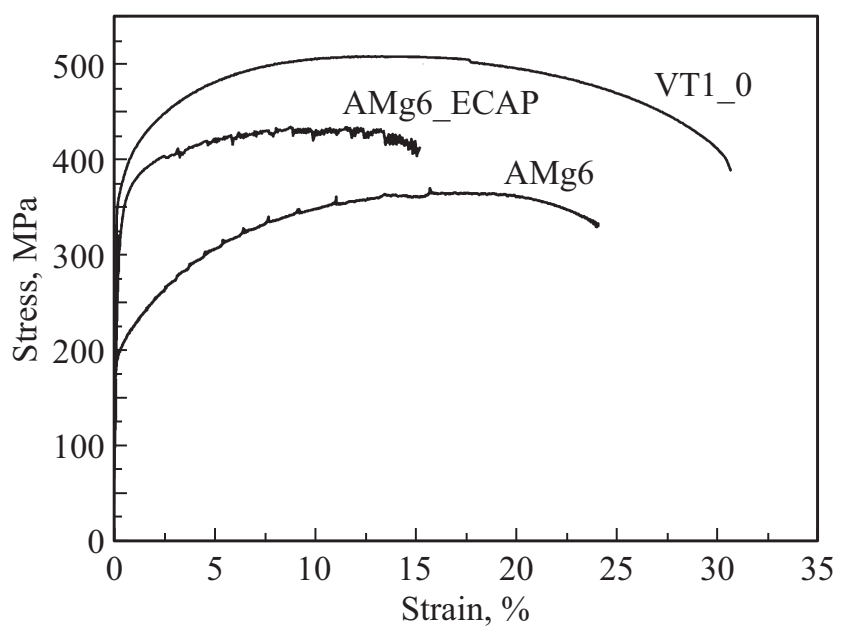

Рис. 1. Диаграммы деформирования AMg6, AMg6 после РКУП обработки и VT1_0.

нагружения не являются гарантией прочности материала при повышении скорости деформирования. Для выявления особенностей деформирования выбранных материалов рассмотрим два типа экспериментов динамическое растяжение и высокоскоростную эрозию твердыми кварцевыми частицами.

Эксперименты на динамическое растяжение выполнялись на башенном копре Instron CEAST 9350. Геометрические размеры рабочей части, также как и в статических экспериментах, составляли $5 \mathrm{~mm}$ в длину и $2 \mathrm{~mm}$ в ширину. Подробно применяемая методика растяжения малых образцов представлена в [8]. В ходе эксперимента фиксировалось изменение усилия, необходимого для деформирования образца. В качестве пороговых характеристик прочности материала выбирались усредненные максимальные усилия при реализуемых скоростях разрывающего напряжения.

Для анализа пороговых величин разрушения образцов был применен структурно временной подход. В качестве критерия разрушения материала использовался вариант критерия инкубационного времени $[10,11]$ :

$$
\frac{1}{\tau} \int_{t-\tau}^{t} \frac{\sigma(s)}{\sigma_{U T S}} d s \leq 1,
$$

где $t$ - время, $\sigma$ - зависимость разрывающего напряжения от времени, $\sigma_{U T S}-$ временное сопротивление разрыву, $\tau$ - инкубационное время разрушения. Параметр $\tau$ находится в рамках рекуррентной процедуры по

Механические характеристики материала

\begin{tabular}{c|c|c|c|c|c}
\hline & $\sigma_{0.2}, \mathrm{MPa}$ & $\sigma_{U T S}, \mathrm{MPa}$ & $\delta, \%$ & $H v$ & $\tau, \mu \mathrm{s}$ \\
\hline AMg6 & 180 & 359 & 24 & 113 & 9 \\
AMg6_ECAP & 215 & 430 & 15 & 149 & 15 \\
VT1_0 & 284 & 495 & 30 & 174 & 39
\end{tabular}

поиску наилучших комбинаций параметров для соответствия расчетных значений экспериментальным точкам.

В качестве второго эксперимента рассматривалось эрозионное воздействие твердыми кварцевыми частицами на установке аэродинамического типа $[7,12]$. В процессе эксперимента варьировалась скорость воздушного потока от 50 до $300 \mathrm{~m} / \mathrm{s}$ с шагом $50 \mathrm{~m} / \mathrm{s}$. Время экспозиции составляло $5 \mathrm{~min}$. При средней размерности частиц $109 \mu \mathrm{m}$ их скорость менялась от 42 до $146 \mathrm{~m} / \mathrm{s}$. Образцы были изготовлены в виде половины диска диаметром $15 \mathrm{~mm}$. В процессе эксперимента фиксировалось изменение массы образца. Как правило, разрушение, сопровождающее эрозионное воздействие, сложно поддается прогнозированию [13]. В рамках настоящего исследования результаты эрозионного нагружения приводятся для иллюстрации особенностей высокоскоростного деформирования.

\section{3. Результаты и обсуждение}

Предел кратковременной прочности при растяжении малых образцов в зависимости от скорости роста напряжений для исследуемых материалов представлен на рис. 2. Расчеты выполнялись по формуле (1) с учетом параметров материала, представленных в таблице. Данные демонстрируют различную скоростную чувствительность материалов. Как и в статическом диапазоне изменения параметров нагружения в области динамических нагрузок наибольшей прочностью обладает титановый сплав.

При сравнении алюминиевых сплавов можно отметить повышение динамической прочности у материала с ультрамелкозернистой структурой. Обработка методами РКУП позволила повысить прочностные характеристики

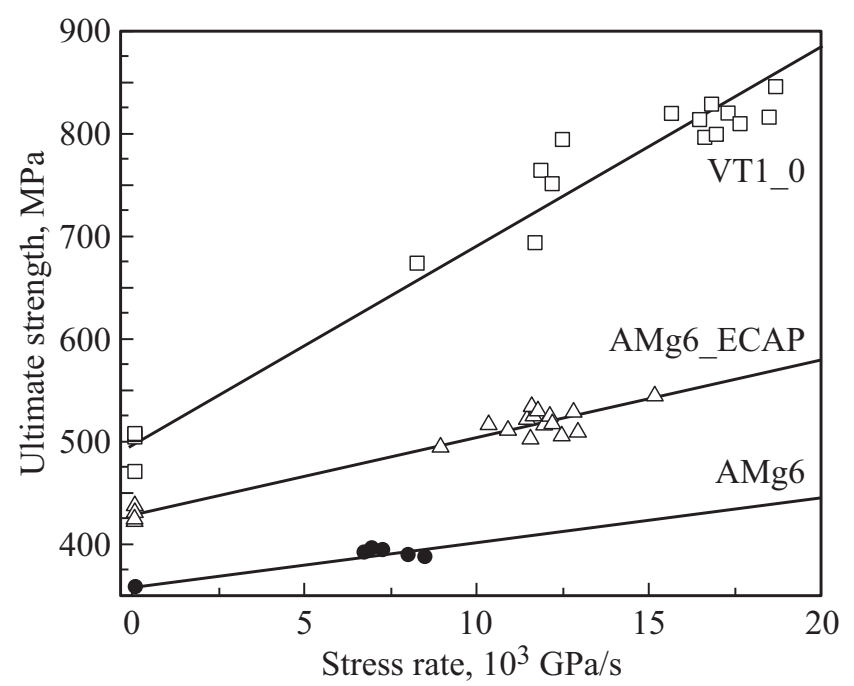

Рис. 2. Зависимость прочности на растяжение от скорости роста напряжений для AMg6, AMg6 после РКУП обработки и VT1_0. Динамические кривые построены по критерию 1 с параметрами материала (таблица). 


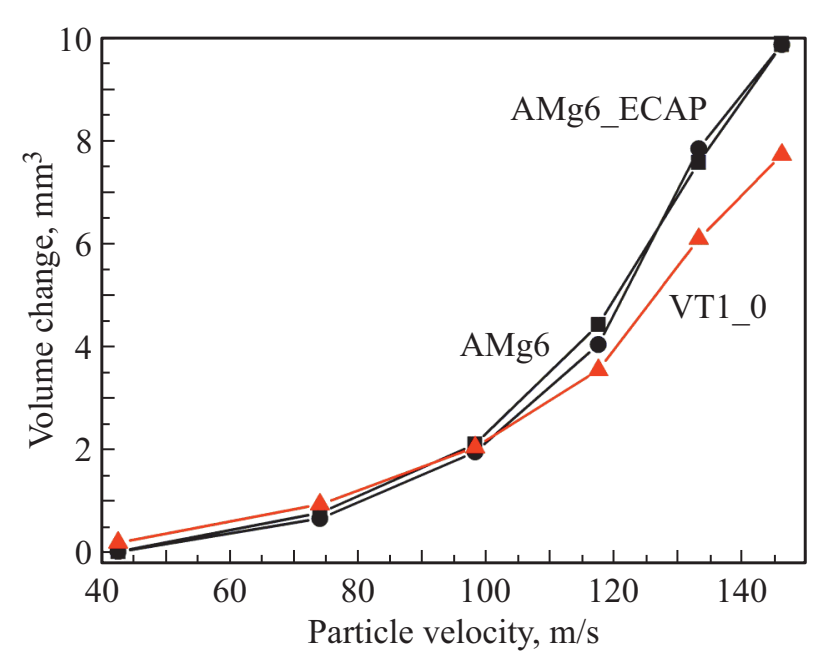

Рис. 3. Изменение объема образцов из $\mathrm{AMg} 6, \mathrm{AMg} 6$ после РКУП обработки и VT1_0 при различных скоростях частиц в эрозионном потоке.

материала, как в статическом, так и в динамическом диапазоне изменения параметров внешнего воздействия.

Полученные в рамках одноосного растяжения данные демонстрируют превосходство титанового сплава над алюминиевыми сплавами. Однако стоит отметить, что одноосное нагружение, это одна из вариаций реальных нагрузок. К примеру, можно рассмотреть эрозионную нагрузку от потока твердых частиц. Этот вид нагружения является импульсным и может приводить к сжатию, сдвигу, растяжению и отколу на различных локальных объемах материала.

Поскольку рассматриваемые материалы сильно отличаются по плотности, сравнение результатов экспериментов по изменению массы некорректно. Поэтому далее рассматривается изменение объема образца, вычисленное путем деления потерянной массы на плотность материала. Изменение объема образцов при длительности экспозиции $5 \mathrm{~min}$ при воздействии двухфазного потока „воздух-кварцевый порошок“ при различных скоростях представлено на рис. 3. Эрозионная стойкость алюминиевого сплава после РКУП обработки практически не изменилась, несмотря на существенное увеличение прочности материала при одноосном растяжении. До скорости $100 \mathrm{~m} / \mathrm{s}$ соударения частиц о поверхность титановый сплав показывает соизмеримые с алюминиевым сплавом результаты. При дальнейшем повышении скорости соударения частиц с поверхностью образца из алюминиевого сплава унос объема материала более существенен, чем у образцов из титана. При скорости движения частиц $146 \mathrm{~m} / \mathrm{s}$ различия составляют более $25 \%$. Такое поведение материалов можно объяснить с использованием структурно временного подхода [14]. У VT1 динамическая прочность в терминах инкубационного времени более чем в два раза превышает динамическую прочность алюминиевых сплавов. По всей видимости, импульс, формируемый кварцевой частицей диаметром $109 \mu \mathrm{m}$ при скоростях менее $100 \mathrm{~m} / \mathrm{s}$ можно отнести к квазистатической нагрузке, поскольку деформация от ударов успевает релаксировать практически полностью. При повышении скорости движения частиц в потоке реализуется нелинейное увеличение поврежденности приповерхностного слоя. У алюминиевых сплавов этот процесс протекает быстрее по причине меньшей динамической прочности, чем у титанового сплава.

\section{4. Заключение}

Выбор материала необходимо проводить под заданные режимы эксплуатации, поскольку при изменении диапазона нагрузок возможно кардинальное ухудшение прочностных характеристик материала, демонстрирующего высокие показатели при статических нагрузках и, наоборот, улучшение свойств материала, на первый взгляд не пригодного для поставленных целей. Выявление структурно временных особенностей деформирования материала и выбор оптимального материала для конкретных условий эксплуатации невозможно без тесного взаимодействия теоретических и экспериментальных подходов.

На примере алюминиевых сплавов AMg6 в исходном и наноструктурированном состоянии, и титанового сплава VT1, продемонстрирован экспериментальнотеоретический подход для выбора материала под экстремальные условия эксплуатации. Первым этапом идет оценка прочности и пластичности, а также поиск путей повышения этих характеристик в условиях квазистатического нагружения. Вторым этапом является проверка динамической прочности выбранных материалов в рамках структурно временного подхода. Третьим заключительным этапом выступает верификация материала в реальных условиях эксплуатации.

В рамках настоящей работы рассматривалось две задачи. Это оценка возможности повышения прочности алюминиевого сплава AMg6 и его применимость в условиях высокоскоростного эрозионного воздействия взамен титанового сплава VT1. Первые два этапа предложенного подхода показали, что титановый сплав имеет большую статическую и динамическую прочность при одноосном растяжении. Но при переходе к эрозионному воздействию твердых части средним размером $109 \mu \mathrm{m}$ на скоростях соударения до $100 \mathrm{~m} / \mathrm{s}$ алюминиевые и титановые сплавы показали одинаковую эрозионную стойкость. Если учесть, что плотность алюминия ниже плотности титана более чем на $50 \%$, то в рассмотренных условиях эксплуатации более предпочтительным оказывается алюминиевый сплав. При этом с использованием методов интенсивной пластической деформации возможно повышение прочностных характеристик материала без потери динамической прочности и эрозионной стойкости. С ростом скорости соударения частиц о поверхность образца выше $100 \mathrm{~m} / \mathrm{s}$ приоритет переходит на сторону титанового сплава. 


\section{Финансирование работы}

Механические и структурные исследования проведены с использованием оборудования лаборатории СПбГУ „Механики перспективных массивных наноматериалов для инновационных инженерных приложений“, ресурсного центра Научного парка СПбГУ „Исследование экстремальных состояний материалов и конструкций“.

Исследование выполнено при финансовой поддержке РФФИ (№ 19-31-60031 и № 20-0-00291).

\section{Конфликт интересов}

Авторы заявляют, что у них нет конфликта интересов.

\section{Список литературы}

[1] Yu.V. Petrov, V.I. Smirnov. Tech. Phys. 55, 230 (2010).

[2] M. Bragov, B.L. Karihaloo, Yu.V. Petrov, A.Yu. Konstantinov, D.A. Lamzin, A.K. Lomunov, I.V. Smirnov. J. Appl. Mech. Tech. Phys. 53, 926 (2012).

[3] W. Goldsmith, J.L. Sackman, C. Ewerts. Rock. Mech. Min. Sci. Geomech. 13, 303 (1976).

[4] S. Howe, W. Goldsmith, J. Sackman. Exp. Mech. 14, 337 (1974).

[5] Y.V. Petrov, I.V. Smirnov, A.A. Utkin. Mech. Solids 45, 476 (2010).

[6] Н.А. Златин, С.М. Мочалов, Г.С. Пугачев, А.М. Брагов. ФTT 16, 1752 (1974).

[7] Н.А. Казаринов, А.Д. Евстифеев, Ю.В. Петров, В.А. Лашков. ДАН 468, 159 (2016).

[8] A.D. Evstifeev, I.V. Smirnov, Yu.V. Petrov. Phys. Solid State 61, 1062 (2019).

[9] R. Valiev. Nature Mater. 3, 511 (2004)

[10] Y.V. Petrov, A.A. Utkin. Sov. Mater. Sci. 25, 153 (1989).

[11] Y.V. Petrov, N.F. Morozov. ASME J. Appl. Mech. 61, 710 (1994).

[12] В.А. Лашков. Инж.-физ.журн. 60, 197 (1991).

[13] Эрозия / Под ред. К. Присс Мир, М. (1982). 512 с

[14] Y.V. Petrov, V.I. Smirnov. Dokl. Phys. 52, 574 (2007).

Редактор Т.Н. Василевская 